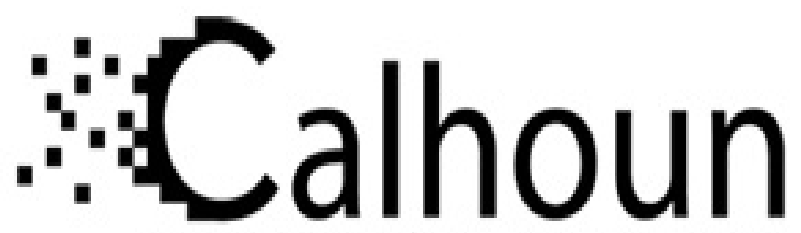

Institutional Archive of the Naval Postgraduate School

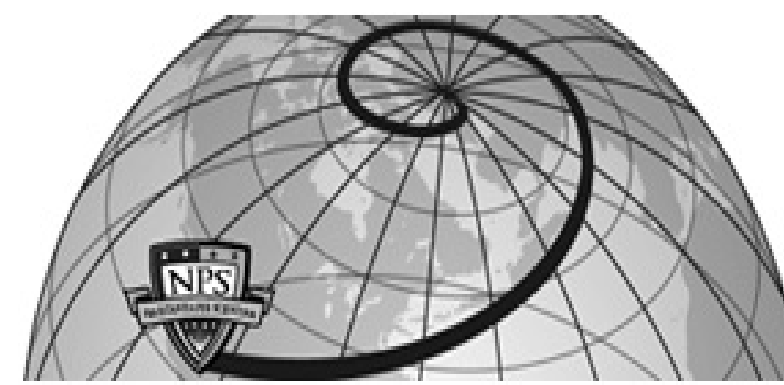

Calhoun: The NPS Institutional Archive DSpace Repository

Avoiding a Second Hollow Force: The Case for Including Crew Endurance Factors in the Afloat Staffing Policies of the U.S. Navy

Miller, N.L.; Firehammer, R.

Miller, N.L. and Firehammer, R. "Avoiding a Second Hollow Force: The Case for Including Crew Endurance Factors in the Afloat Staffing Policies of the U.S. Navy", Naval Engineers Journal, Vol 119:1 pp 83-96, 2007. This paper won the 'Jimmie' Hamilton Award for Best Paper of 2007 from The American Society of Naval Engineers. https://hdl.handle.net/10945/36520

This publication is a work of the U.S. Government as defined in Title 17, United States Code, Section 101. Copyright protection is not available for this work in the United States.

Downloaded from NPS Archive: Calhoun

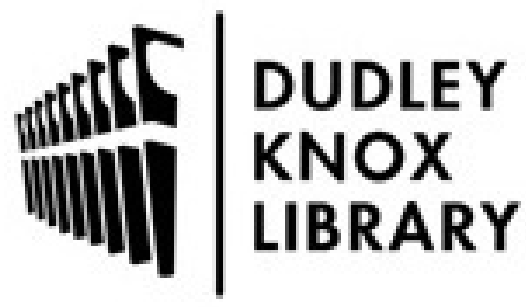

http://www.nps.edu/library
Calhoun is the Naval Postgraduate School's public access digital repository for research materials and institutional publications created by the NPS community. Calhoun is named for Professor of Mathematics Guy K. Calhoun, NPS's first appointed -- and published -- scholarly author.

Dudley Knox Library / Naval Postgraduate School 411 Dyer Road / 1 University Circle Monterey, California USA 93943 


\title{
Avoiding a Second Hollow Force: The Case for Including Crew Endurance Factors in the Afloat Staffing Policies of the US Navy
}

\author{
Nita Lewis Miller and Robert Firehammer
}

\begin{abstract}
Hbstract
In order to meet its obligations for prompt and sustained combat at sea, the US Navy relies on sailors to perform relentlessly while underway in highly stressful combat environments. The Navy currently uses an afloat staffing policy that is calculated using a 70-hour workweek per sailor metric. However, this construct fails to factor in an individual sailor's capacity to sustain performance and is based instead on a notional Navy standard workweek. Part of the inadequacy of the current staffing policy results from its failure to consider an inviolable and basic physiological requirement for adequate sleep and rest for sailors. Research indicates a strong causal relationship between sleep and performance. When deprived of sleep, either chronically or acutely, human performance suffers in a dramatic and predictable manner. These performance decrements have even been equated to the effects of alcohol. If the US Navy is to deliver the combat capability demanded by our government and stated in Navy governing documents, sleep and rest requirements must be accounted for in staffing methodologies. To achieve full combat capability, the Navy must change its culture and adopt programs that promote crew endurance. Human system integration can provide a means to accomplish this goal.
\end{abstract}

\section{Background}

In 1973, the US Navy transitioned from the conscription force of the Vietnam era to an allvolunteer force. A side effect of this change was a reduction in force and a high turnover of Naval personnel. Consequently, the Navy then experienced a period in the mid- to late-1970s, commonly referred to as the "Hollow Force," characterized by deficiencies in manpower, technical skills, and leadership. Many believed that this relatively inexperienced workforce was less capable of delivering the combat requirements demanded by our nation. In an effort to reverse this trend, the Navy, under the direction of the Reagan Administration, changed its overall management strategy and personnel policies to improve personnel retention. These changes resulted in a more experienced workforce, as measured by the force profile's average length of service. These actions had the desired effect: they improved the Navy's combat capability by deploying a more experienced and capable workforce and may have played a major role in winning the "Cold War."

\section{Introduction}

Since the end of the Cold War and the absence of an immediate naval threat, the US Navy has instituted cost-cutting measures that may risk creation of a second "Hollow Force." The physical and cognitive attributes of sailors may well represent our Navy's greatest strength. However, 
these human attributes, if not properly managed, can become weaknesses and must be accounted for in the methodologies used to staff our afloat platforms.

The current workload standard used by the Navy for determining the afloat manpower requirements does not accurately reflect the sailor's ability to sustain performance while operating in a wartime environment. This flaw, coupled with efforts to reduce afloat manpower requirements from the " $M+1$ metric" to a "billets authorized is good enough" construct, combines with optimal manning initiatives to jeopardize the ability to carry out the Navy's wartime mission.

This paper addresses the immutable degradations in human performance due to chronic and acute sleep deprivation and examines the role of human performance in the staffing methodologies used by the US Navy. Additionally, we address how the Navy's operational culture may further contribute to degraded performance by sailors while they are at sea. Much of this information is drawn from the large body of empirical research focused on the relationship between sleep requirements and human performance. As in any military staffing methodology, the desired end state is an effective war fighting machine, capable of carrying out its assigned missions in support of our nation's interests and goals. To achieve those ends, sustained human performance should be the governing metric from which to determine the correct numbers of sailors needed to staff our ships, submarines, and aircraft squadrons. However, ensuring that our sailors are prepared to carry out their assignments and duties in a sustained combat environment will require changes to the Navy's culture: specifically, the implementation of programs focused on managing human performance and fatigue levels.

\section{The Mission of the US Navy}

The US Navy is charged by law to staff its platforms for sustained combat at sea. Specifically, Title 10 of the United States Code, Subtitle C, Part 1, Chapter 507, Article 5,062 states: (a) The Navy, within the Department of the Navy, includes, in general, naval combat and service forces and such aviation as may be organic therein. The Navy shall be organized, trained, and equipped primarily for prompt and sustained combat incident to operations at sea. It is responsible for the preparation of naval forces necessary for the effective prosecution of war except as otherwise assigned and, in accordance with integrated joint mobilization plans, for the expansion of the peacetime components of the Navy to meet the needs of war.

It is the term "sustained combat" that is of primary interest in this paper. We believe it is difficult, perhaps impossible, to achieve sustained combat capability if sailors are incapable of sustaining the level of performance required by this statute. The phrase "sustained combat incident to operations at sea for the effective prosecution of war" is defined:

Operate offensively in a high density, multithreat environment. The most demanding operating environment anticipated is operations at sea in wartime in cooperation with designed joint/allied forces, including operations involving coordination of land and sea-based aviation. Peacetime forward operations in littoral areas are almost equally demanding. These operations are frequently characterized by confined and congested water and air space occupied by friends, adversaries and neutrals—making identification and coordination profoundly difficult. In this environment, our adversaries can concentrate and layer their defenses. In an era when even Third World countries possess sophisticated weaponry, surprise attack can be anticipated by submarines, coastal missiles, mines, sea-skimming cruise missiles and theater ballistic missiles.

Additionally, afloat combatant platforms are to be capable of performing all assigned primary mission areas simultaneously, while maintaining readiness Conditions I, II, and III (wartime/ forward deployment cruising readiness).

- Under Condition I, sailors can be expected to perform for up to 24 hours.

Under Condition II, the maximum expected duration is 10 days, with a minimum of 4-6 hours of rest provided per man per day. 
Under Condition III, the maximum expected crew endurance is 60 days, with an opportunity for 8 hours of rest provided per man per day.

The operational requirements described above indicate a need for sailors to be vigilant, responsive, and adaptive-all traits a human possesses. However, vigilance, responsiveness, and adaptability are known to degrade in highly stressful situations and while operating under significant sleep deprivation, and the maritime operating environment under combat conditions is characterized by both high stress and reduced sleep.

\section{Workload per Sailor Hssessment: Building the Navy's Standard Productive Workweek}

The operational requirements stated above become part of several considerations in the Navy's afloat manpower requirements determination process. To meet these requirements, the Navy uses an afloat manpower requirements determination process centered on the Navy's standard productive workweek. The standard productive workweek is an element of the Navy's standard workweek as described in OPNAVINST 1000.16J and shown in Table 1. As can be seen in the table, the standard productive workweek in 2001 was 67 hours.

Also shown in Table 1, sailors are scheduled to receive 56 hours of sleep per week, presumably 8 hours per day. Most experts agree that adult humans require approximately 8 hours of sleep per day. It is important to note that research has overwhelmingly determined that the quantity, the quality, and the timing of sleep are all critical factors that must be considered when determining how long human performance can be sustained. In other words, 8 hours of sleep during daylight hours under disrupted conditions is not equivalent to 8 hours of sleep at night under ideal conditions.

In 2000-2001, the Center for Naval Analysis (CNA), under contract to the Chief of Naval Operations (CNO) N1, conducted a manpower study of afloat units to determine the average hours that sailors work at sea. The report was entitled "Hours of Work at Sea: An Empirical Analysis." Before this 2001 study, the last time the Navy conducted a workweek study was in the 1970s. At the time of the CNA study, the Navy's standard workweek was reflected in the data in Table 1. Researchers at the CNA collected data from one vessel per class of surface ship that was deployed to the Mediterranean Sea and Indian Ocean in 2000. Table 2 displays the weekly average number of productive work hours per sailor on those ships.

This effort revealed a discrepancy between the actual hours sailors work and the Navy's productive workweek policy. The CNA study reported an 8-hour discrepancy between the Navy's productive work policy of 67 hours per week and the average hours (75.1 hours) the sailors were reported to be working. It should be noted that the shortest workweek reported by the CNA study was 70.8 hours for sailors on the LHD, while sailors on the CG averaged

\section{TABLE 1: US Navy Standard Workweek Circa 2001}

\begin{tabular}{lc}
\multicolumn{1}{c}{ Activity } & Hours \\
\hline On-duty time (all work) & 81 \\
\hline Productive work & 67 \\
\hline Training & 7 \\
\hline Service diversion & 7 \\
\hline Unavailable time & 87 \\
\hline Sleeping & 56 \\
\hline Messing & 14 \\
\hline Personal needs & 14 \\
\hline Sunday & 3 \\
\hline OPNAVINST (1000.16J).
\end{tabular}

TABLE 2: Productive Work Hours: Weekly Estimates from Center for Naval Analysis (CNA) 2001 Study

\begin{tabular}{|c|c|c|c|c|}
\hline Ship Class & Watch + Ship's Work & Evolutions & General Qtr & Wkly Total \\
\hline LHD & 65.8 & 2.2 & 2.8 & 70.8 \\
\hline LSD & 72.6 & 4.8 & 0 & 77.4 \\
\hline CVN & 69.9 & 1.4 & 2.7 & 73.7 \\
\hline DDG & 73.4 & 4.7 & 0 & 78.1 \\
\hline C & 65.4 & 14.8 & 0 & 80.2 \\
\hline Average & 69.5 & 4.0 & 1.6 & 75.1 \\
\hline
\end{tabular}


80.2 hours-a difference of almost 10 hours.

The study also strongly recommended the need for further assessment of the workweek, calling other issues into question as well. Additional questions to be addressed included:

Why was there such variation between platforms? If this is real, does each platform have a unique, productive workweek?

Under those work and operating conditions, was sailor performance acceptable?

What is the workload variation within each platform? Do all sailors on a given platform work the same number of hours? Are there differences between departments, divisions, or work centers?

Does the manpower requirements determination process account for the entire workload? Does it include training and military requirements?

Do staffing levels below billet requirements lead to sailors working longer hours? If so, what are the sailors sacrificing to cover the increased workload?

Unfortunately, the CNA study had insufficient data to draw conclusions on these questions. However, one variable, sleep amount, can be estimated from the report. As can be seen in Table 3, the sailors in this study were getting an average of 49.4 hours of sleep per week or roughly 7 hours of sleep per day-an hour less than the Navy's Condition III guidance of 8 hours per day. Sleep amount varied by ship class, with the CG sailors getting the least sleep (46.8 hours per week) and

\section{TABLE 3: Off-Duty Time}

\begin{tabular}{lccccc} 
& & & \multicolumn{4}{c}{$\begin{array}{c}\text { Other } \\
\text { Personal }\end{array}$} \\
Ship Class & $\begin{array}{l}\text { Physical } \\
\text { Training }\end{array}$ & Sleeping & Messing & Time & Total \\
\hline LHD & 3.4 & 52.2 & 11.7 & 21.8 & 89.1 \\
\hline LSD & 1.6 & 48.5 & 10.8 & 20.1 & 81.0 \\
\hline CVN & 2.5 & 49.8 & 9.6 & 18.6 & 80.5 \\
\hline DDG & 2.1 & 47.8 & 7.7 & 19.3 & 76.9 \\
\hline CG & 3.3 & 46.6 & 8.7 & 18.2 & 77.0 \\
\hline Average & 2.6 & 49.4 & 9.6 & 19.4 & 81.0 \\
\hline Center for Naval Analysis Study (2001).
\end{tabular}

LHD sailors reporting an average of 52.2 hours.

Three major drawbacks of the study, as cited by the authors, were:

Insufficient sample size. With only one ship per class studied, there were not enough data (reflected in Tables 1-3) to detect actual differences that may have existed. With such small sample sizes, it becomes impossible to tease out the variance explained by factors such as differing mission, the uniqueness of the command, and/or the context of the current geopolitical environment.

Data stratification. It was not clear whether a representative sample was collected for all categories of sailors. The study may not have stratified or collected adequate numbers for analyzing all pay grades, departments, divisions, or work centers.

Workload. Most importantly, the study did not address the workload the sailors should/ would be performing while operating in a wartime environment. The CNA study was conducted in the Mediterranean Sea and Indian Ocean while the fleet was deployed, but not at war. Therefore, the study did not reflect the work schedules associated with the operational tempo during wartime.

Soon after the 2001 CNA study, the Navy changed its Standard Navy Workweek by increasing the Productive Work category from 67 to 70 hours and reducing Service Diversion from 7 to 4 hours. As can be seen in Table 4, the new Productive Work of 70 hours/week became the Navy standard for use as the foundation for all afloat manpower requirements. While this change decreased the manpower requirements per platform, it did not reduce the total actual workload that still must be performed for each ship.

The afloat manpower requirement represents the number of humans required to optimally operate a weapons system or other functions required to keep the vessel operating. 
Determining sailor performance as a function of the manpower requirements determination process has both qualitative and quantitative elements. The quantitative aspects of sailor performance are presumed to be associated with the Standard Productive Workweek (70 hours per week). However, this workloaddriven approach to requirements determination does not reflect a Sailor's ability to sustain the required level of performance throughout a wartime scenario. Research suggests that sustainment of human performance is more closely related to the amount and quality of sleep than it is to the workload level alone. In light of this information, we suggest that these guiding principles are necessary for calculating the human part of the afloat staffing level equation:

Sailors (or the human capability embodied in sailors) are an essential element of a warfare system.

Sailors represent the most important component in a system; however, sailors may also represent the most vulnerable system component because they are unable to operate continuously and are subject to fatigue.

The sailor must be able to sustain a high level of performance throughout the entire wartime scenario.

\section{Maintenance Requirement for Humans}

A weapons system can be divided into component parts: mechanical, electrical/electronic, and human elements are all components of the system. Typically, the mechanical and electrical/electronic components will receive periodic preventative maintenance to keep those parts of the system operating as designed. The human element has periodic maintenance requirements as well, including nourishment, hygiene, and sleep. Failure to conduct these basic maintenance requirements will result in physical and mental deterioration of the human body. Research clearly shows that when humans experience sleep deficits, their cognitive processes are significantly reduced. Under reduced or restricted sleep

\section{TABLE 4: Current Standard Navy Workweek}

\begin{tabular}{lc}
\multicolumn{1}{c}{ Activity } & Hours per Week \\
\hline On-duty time (all work) & 81 \\
\hline Productive work & 70 \\
\hline Training & 7 \\
\hline Service diversion & 4 \\
\hline Unavailable time & 87 \\
\hline Sleeping & 56 \\
\hline Messing & 14 \\
\hline Personal needs & 14 \\
\hline Sunday free time & 3 \\
\hline OPNAVINST (1000.16J CH-1).
\end{tabular}

conditions, the following characteristics have been observed:

We do not think clearly;

We become irritable;

We do not communicate well with each other;

We become withdrawn and less willing to resolve issues and problems;

Our ability to ward off disease is impaired;

We experience fatigue throughout our work and leisure hours; and

- Our ability to carry out mental tasks is compromised.

Thus, when we do not get sufficient sleep, we compromise our health and safety and the safety of those around us.

\section{Sleep in Humans}

In normal humans, sleep occurs in roughly 90 minute cycles that repeat over the course of an 8-hour primary sleep period (see Figure 1). Sleep is categorized into two distinct classes known as

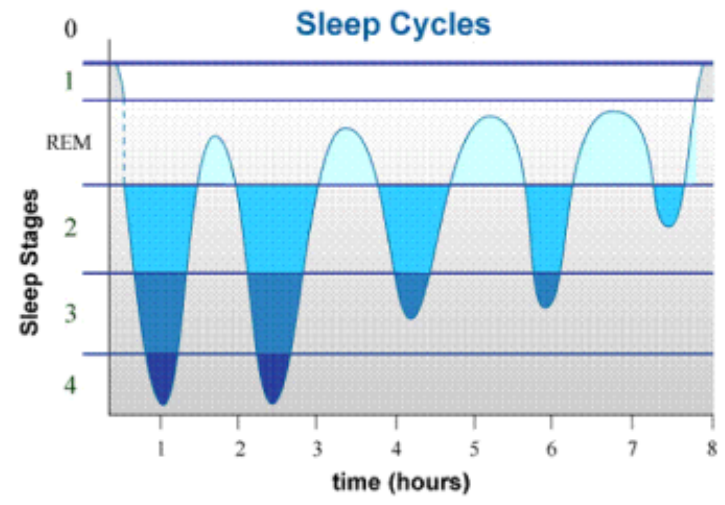

Figure 1: Sleep stages in the normal adult human (Miller Matsagas, and Shat tuck in press) 
nonrapid eye movement (NREM) sleep and rapid eye movement (REM) sleep. NREM can be further divided into five sleep stages: Stage 0 (awake) and Stages 1-4, which correspond to increasingly deeper sleep. Each stage depicted in Figure 1 is necessary for and uniquely contributes to the human body's restorative process. Disruptions in any of these stages that lead to full wakefulness lessens the sleep benefit to the individual. Sleep deprivation can result from frequent disruptions of the normal sleep cycle as well as from foreshortened sleep periods.

The human need for sleep is a physiologically driven event that dominates our daily activities and is central to our ability to perform both physical and cognitive tasks. The quantity and quality of sleep, to a great extent, determine how well humans function within a system. Much of the variance in human performance is accounted for by three underlying and well-documented mechanisms that are integrally related to sleep:

Human performance fluctuates based on fatigue due to acute or chronic sleep deprivation. Most adult humans require an average of 8 hours of sleep per day. Like many naturally occurring processes, the requirement for sleep is normally distributed, with some individuals requiring more than 8 hours of sleep and some individuals requiring less. When this sleep requirement is not met, performance can suffer dramatically.

Substantial differences in performance are due to normal circadian variation. The human circadian rhythm is a human's natural daily cycle and governs things such as hormone release and alertness.

A third source of performance variation results from disruption of circadian rhythms from jet lag or shift work. Any traveler transiting time zones, particularly traveling east, will testify to the cognitive challenges posed by jet lag. The literature on shiftwork is rife with examples of diminished performance and health risks associated with working night shift and swing shift schedules. Both of these conditions, diminished performance and health risks, are partly due to disrupted circadian rhythms or "circadian desynchrony." A comprehensive review of the effects of sleep on performance in military operations is available in (Miller, Matasagas, and Shattuck in press).

\section{Impact of Insufficient Sleep on Human Performance}

Some aspects of performance are more susceptible to sleep deprivation than others. Given that sleepiness causes increased eye blinks, longer eye closure durations, even brief bursts of sleep called "microsleep," it is understandable that tasks depending on visual input are particularly sensitive to sleep disruption (Wickens et al. 2004). Studies have demonstrated that individuals whose jobs require them to perform vigilance tasks (e.g., monitoring visual displays with little or no external visual stimulation) tend to miss subtle pattern changes. This vigilance decrement has major implications for the Department of Defense (DoD), given that individuals standing watch in combat information, fire control, and sonar stations may be required to monitor visual or auditory displays for extended periods of time.

In addition to the DoD, the Federal Railroad Administration (FRA) has also been interested in the safety implications of sleep deprivation, serving as a key player in developing strategies to mitigate the effects of sleep deprivation in rail mishaps. Joint funding from the DoD and FRA has enabled the development of the Fatigue Avoidance Scheduling Tool (FAST). This tool is based on the Sleep and Fatigue Task Effectiveness (SAFTE) model and uses an individual's 72 hour sleep history to predict current performance level or "predicted effectiveness" (Hursh et al. 2001).

Two groundbreaking studies demonstrate the direct relationship between an individual's performance and the amount of sleep they receive. One study, conducted at the Walter Reed Army Institute of Research (WRAIR), looked at the effects of 3,5, 7, and 9 hours of sleep per night (Belenky et al. 2003), while the other looked at 
4,6 , and 8 hours of sleep per night (Van Dongen et al. 2003). In the WRAIR study, researchers examined how varying sleep levels impacted human performance (Figure 2).

Baseline data were collected for 3 days on all participants. Participants were randomly assigned to one of the four sleep groups: 3, 5, 7, and 9 hours of sleep per night. For 1 week following the baseline, participants received a series of tests to evaluate their reaction times to a visual stimulus. The results of this study showed a dose-response relationship between amount of sleep and human performance. The less sleep received, the worse the performance. Quite surprising to the researchers was the fact that human performance remained below normal levels for at least 3 days following participants' return to normal 8 hours per night sleep conditions. In addition, participants were unable to accurately assess the level of degradation in their performance, asserting that they have achieved baseline levels when their performance was still significantly degraded.

A closely related dose-response study of sleep and performance examined 4,6 , and 8 hours of sleep (Van Dongen et al. 2003). In their 2-week experiment on 36 participants, time in bed was held constant each day (no shiftwork scheduling). Participants were given neurobehavioral tests every 2 hours while awake. The results showed that participants receiving progressively less sleep have worse task performance than those who receive more sleep. The group in the 4-hour time in bed condition exhibited the greatest reduction in performance, while the smallest performance reduction was seen in the 8 -hour time in bed condition.

A second part of their experiment sought to account for the differences between individual sleep need and vulnerability to sleep loss. A battery of tests was conducted on a separate group of individuals to assess individual variability on these two factors. The results from both experiments concluded that the estimated need for sleep was 8.2 hours per day,

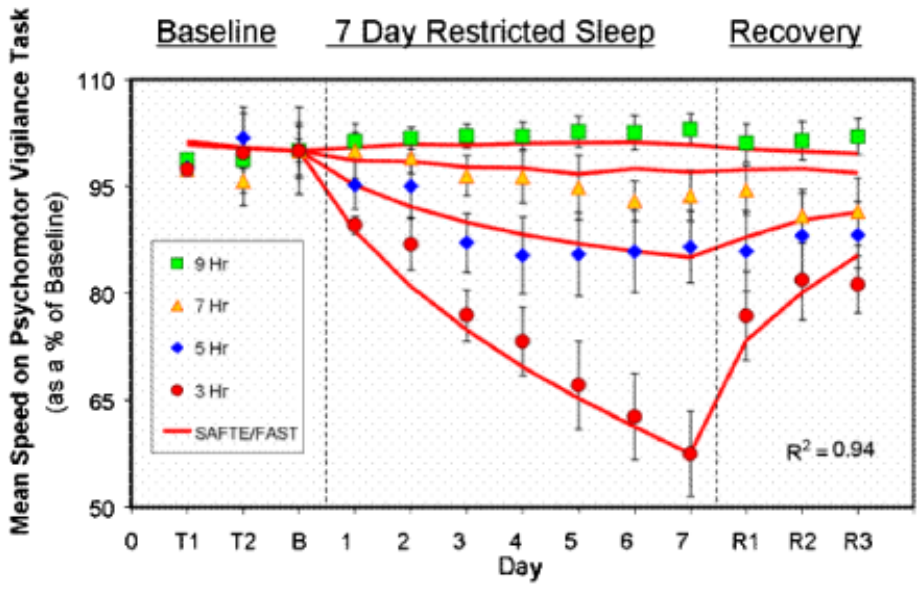

Figure 2: Dose-response relationship between sleep and performance (Belenky et al. 2003)

with a variation of 2.6 hours. Thus, under conditions of chronic sleep restriction, sleep debt may be defined as the cumulative hours of sleep loss with respect to the participant'sspecific daily need for sleep. These results indicate that some participants can function well with less than 8 hours of sleep, while others require significantly more sleep to retain their normal level of performance.

The Naval Postgraduate School (NPS) conducted a study to examine how varying the sleep allowance from 6 to 8 hours impacted academic performance at the Recruit Training Command (RTC) or Navy "Boot Camp" (Miller et al. 2004; Andrews 2004). See Figure 3.

Academic data, in the form of standardized test scores, were collected for 3 years of recruits, representing cohorts from 2000, 2001, and 2003. (Data from 2002 were not included in the current study because the sleep schedule was changed in the middle of the year.)

Those who received 6 hours of sleep per night (Year 2000 and 2001) had similar scores on standardized tests $($ mean $=3.9$ ). The 2003 cohort received 8 hours of sleep, an additional 2 hours per night. This 8-hours-per-night group had significantly higher scores ( mean $=4.5$ ), representing a $15.4 \%$ 
improvement in performance. (Recruits who did not finish training (attrites) were removed from the analysis.) While other factors in the training environment and regimen of these US Navy recruits were also changed during this time period, the striking improvement in their standardized tests scores is in keeping with research showing improved learning and memory with additional sleep. This study indicates that sleep is important to learning for these young recruits.

In addition to simple sleep deprivation, the timing and quality of sleep play a significant role in a human's ability to sustain performance. Eight hours of fragmented sleep per day, while better than no sleep at all, is of lesser quality than contiguous sleep. Additionally, napping can improve human performance but is less effective at restoring performance than contiguous, quality sleep (Godfrey 2006).

\section{Maritime Studies of Human Performance and Sleep}

Humans operate on an approximate 24-hour biological clock with a predictable pattern in many parameters of our behavior. A proper appreciation of performance decrements, seen in individuals whose circadian rhythms are desynchronized, serves as a reminder of the importance of adequate rest for all crew members. Watchstanding schedules specifically designed to safeguard against fatigue and promote sleep hygiene are vital.

Figure 3: US Navy recruits (Great Lakes) standardized test scores by year, 6 versus 8 hours of sleep (Miller et al. 2004; Andrews 2004)

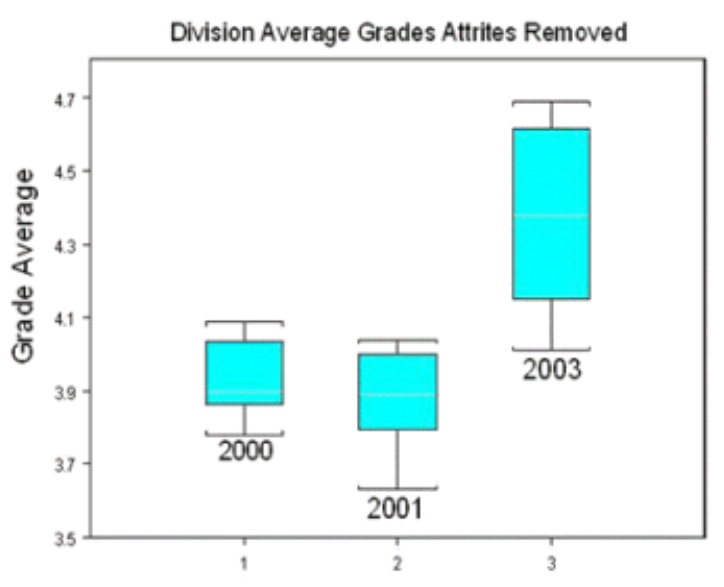

Shiftwork is a persistent maritime issue due to the requirements for full-time, around-the-clock watchstanding. The traditional Naval watch rotation schedule, 4 hours on watch and 8 hours off watch, along with periodic requirement to "dog the watch," results in sleep disruption due to both fragmented recovery sleep and desynchrony of the body's circadian rhythm. Sailors working the night shift are awake when their bodies tell them they should be asleep and trying to sleep when their internal clocks think they should be awake. Research indicates that sailors working the night shift, especially those exposed to sunlight before trying to sleep, have trouble getting quality sleep during daytime hours due to this physiological sleep/wake conflict (Miller and Nguyen 2003).

The US Coast Guard (USCG) has conducted a number of human fatigue studies in the civilian mariner domain as well as examined the impact that USCG operations, especially the 4 hours on and 8 hours off watch rotation, has on sailors' ability to remain vigilant while on duty.

One USCG study (Sandquist et al. 1996) sought to identify the nature and extent of sleep disruption-induced fatigue in the commercial maritime industry and identify the impact of watch duration on personnel fatigue. The study was conducted on 141 mariners from eight commercial ships (six tankers and two freighters). Data were collected on their work and sleep patterns, as well as a variety of other data pertinent to fatigue. The incidence of critical fatigue indicators such as severely restricted sleep duration per 24-hour period, rapid sleep onset at bedtime, and critically low alertness levels suggests that fatigue regularly occurs in this population. The study concluded the following about the nature and extent of the fatigue problem. Critical levels of fatigue occur between $8 \%$ and $21 \%$ of the time, driven primarily by personnel on the 4 hours on and 8 hours off watch schedule. Recovery sleep periods do not occur. Mariners sleep an average of 6.6 hours per 24-hour period while on shipboard duty-1.3 hours less than 
their average sleep duration at home. Watchstanders generally obtain less total sleep (6.6 hours) than other personnel, and the sleep is of a lower quality due to fragmentation and physiologically inappropriate sleep times. The study also found inconsistent levels of alertness over the watchstanding period and a substantial decline in alertness on the 20:00-24:00 hours watch. Additionally, they found a significant decline in alertness for the 04:00-08:00 hours watch personnel and an overestimation of alertness by 00:00-04:00 watch personnel. The study concluded that a fatigue problem exists in the US maritime industry. The research points to sleep disruption, reduced time between watches, fragmented sleep, and long workdays as principal contributors to the problem.

Another USCG study (Comperatore et al. 1999) examined the incidence of sleep loss and wakefulness degradation under the USCG's

EXEMPLAR crewing project. The EXEMPLAR crewing project explored the potential use of reduced crew complements aboard high-

endurance cutters. One major concern is that reductions in crew size may exacerbate crew fatigue and ultimately compromise safety. The central objective of this study was to determine crew fatigue levels while sailing under EXEMPLAR crew reductions. This study was conducted aboard the USCG Cutter MUNRO during a patrol from Tokyo, Japan, to Pearl Harbor, Hawaii. Daily evaluations of alertness (maintenance of wakefulness) and of the stability of the sleep/wake cycle (variability of sleep duration and timing) were used to characterize fatigue levels throughout 30 consecutive days on patrol. Sleep (including sleep latency onset) was assessed using ambulatory electro-encephoalography (EEG) in 14 crew members. Forty-three volunteers participated in the daily sleep evaluations by wearing wrist-worn activity monitors. The actigraphy data showed that $61.5 \%$ of all scored sleep profiles exhibited severely disrupted sleep patterns. The study also found that those sailors who failed to maintain wakefulness also experienced frequent sleep disruptions and typically received less than 6 hours of sleep per day.
Watch schedules requiring frequent rotations from daytime to nighttime (24:00-04:00) and early morning (04:00-08:00) duty hours contributed to disruption of sleep/wake cycles.

Comperatore et al. (1999) conducted another study aboard the USCG's DEPENDABLE. The study examined crew sleep and fatigue during a 32-day transit from Portsmouth, Virginia, to Halifax, Nova Scotia. Alertness tests were administered within 3 hours of awakening from daily sleep. The study showed a $59 \%$ incidence of sleep/wake cycle disruption associated with high failure rates in EEG alertness tests. Twelve out of the 14 participants failed to maintain wakefulness in $50-100 \%$ of the tests.

These USCG studies were conducted while the vessels were on independent transit and during normal sea conditions. However, the analysis concluded that crew endurance levels during those low tempo operations were considered less than optimal. If the study had been conducted under more stressful operational tempo or deteriorating weather/sea conditions, an even higher incidence of fatigue conditions would be expected. The studies had the following four recommendations:

Implement crew endurance education programs to optimize underway crew rest and prevent sleep disruption.

Design watch schedules that minimize sleep/ wake cycle disruptions.

Develop a system to optimize the number of watch-qualified personnel underway to reduce the frequency of rotations into the 24:0004:00 or 04:00-08:00 hours watch schedules. (EXEMPLAR Project only) Implement physical improvements to sleeping areas to improve sleep quality.

Subsequent to these studies, the USCG initiated a one in four watch rotation to address the issue of fatigue in their watchstanders. They have as instituted a "crew endurance management" program throughout the entire service. 


\section{Sleep Disruption Due to Shiftwork}

Sleep disruption occurs in many professions, but perhaps none more so than in the maritime domain. Sleep is disrupted as a result of nighttime evolutions such as entering or leaving port, underway replenishment, and the normal watch rotations of key operating stations. During Operation Enduring Freedom, the Navy was required to conduct combat operations around the clock. To accomplish this mission, sister carriers shared 12-hour shifts, one working days and one working nights. The entire carrier shifted to a night schedule to support this mission. Miller and Nguyen (2003) conducted a study of sailor sleep patterns on USS JOHN C. STENNIS during Operation Enduring Freedom while the carrier was working night operations. The study, conducted on 28 participants, measured the amount and quality of sleep via wrist activity monitors (ActigraphTM). The FAST was used to calculate predicted effectiveness based on the data produced from the ActigraphTM. The NPS study found significant differences in sleep patterns between those individuals working topside and below decks (Table 5).

The study found tremendous differences in sleep between individuals working topside and those working below decks. It concluded that exposure to sunlight immediately before bedtime degraded the sleep of those individuals working topside. Many below decks personnel do not stand 4-on/8-off watches, instead performing mainly maintenance responsibilities. A study comparing flight deck personnel with non-flight deck watchstanders might serve as a better means of assessing the effects of light on the sleep patterns of sailors working night opera- tions and exposed to daylight immediately before bedtime.

\section{Sailor Performance While Fatigued}

These maritime studies clearly identify a direct correlation between shiftwork, sleep disruptions, and degraded human performance. The preceding studies were conducted under normal independent underway operating conditions (i.e., less than arduous conditions), yet they found severely disrupted sleep patterns. Under combat conditions, it is reasonable to assume that sleep will be even more degraded. The ability of sailors to think and reason while in a fatigued state has significant implications for combat effectiveness. The combat environment adds a much higher level of stress than normal deployed maritime operations. Managing cognitive fatigue has a large role in improving a sailor's endurance in a high operational tempo and high stress combat environment.

\section{Navy's Wartime Environment}

In a wartime situation, ships routinely and frequently cycle from readiness Condition III to Condition II to Condition I as frequently, as the fluid nature of war demands flexible readiness responses to meet the changing threat scenarios. The example from which we might draw some parallels is the British/Argentinean war over the Falkland Islands. The British Navy had to contend with a credible air threat posed by the Argentinean Mirage jets carrying the Exocet cruise missile. The Argentinean Navy possessed a low-risk, subsurface threat from their one serviceable diesel submarine. That lone threat resulted in the British Navy expending an inordinate amount of time and resources to prosecute the contact, both real and false. Likely most, if not all, of those prosecutions

\section{TABLE 5: Average Sleep and Effectiveness Topside versus Below Decks Personnel}

\begin{tabular}{|c|c|c|c|}
\hline & Average Daily Sleep (hours) & Average Sleep per Episode (hours) & \% Time $\mathbf{7 8} \%$ Cognitive Effectiveness \\
\hline Topside & 4.72 & 3.29 & 66 \\
\hline Below decks & 7.35 & 6.83 & 35 \\
\hline
\end{tabular}


were conducted with their ships at a higher state of readiness (Condition I or II) vice the normal wartime Condition III. Each move to a higher battle condition results in the off-watch Sailors losing what little sleep they were receiving and thus becoming that much more ineffective as an integral part of the system designed to prosecute or defend the unit. In a forward-deployed state, the ships will also be participating in refueling at sea evolutions (approximately every 3 days) and replenishing stores (approximately every 7 days). Each of those evolutions constitutes a lost sleep episode.

Under a Falkland Islands-type scenario, the US Navy should expect to frequently cycle into increased readiness postures. Thus, sailors will be expected to remain vigilant for unreasonably long periods of time. In such a scenario, sailors may give everything they have to give for the mission, but due to human physiology and as a result of fatigue brought on by sleep disruption, their best may not be good enough. The end result of a flotilla of sailors holding key operational positions, all operating in severe sleep debt, could be disastrous.

\section{Hfloat Manpower Requirements in a Crew Endurance Construct}

If the Navy is tasked to staff its platforms for sustained combat operations at sea, and if such operations are as arduous and long as those stated in our governing documents, then sustained human performance must be the foundation from which we staff those platforms. If sustained human performance is to become the governing metric, then one should expect the afloat manpower requirements necessary to support continuous combat operations at sea to increase and possibly increase significantly. Recent efforts by the commercial maritime industry regarding work hours within their Standards of Training, Certification, and Watch-keeping (STCW) regulations and the Federal Motor Carriers Safety Administration's (FMCSA) revision of their work-hour regulations show that sleep and time of day are as important as "how long" people work when it comes to readiness and safety.

Both of these organizations imposed minimum continuous sleep-length requirements and maximum work limits per 24-hour periods. While most manning analyses take into consideration time for sleep, they do not consider the fact that sleep should occur in one uninterrupted period of at least 8 hours. In order to guarantee this continuous 8-hour period for sleep, one would need to provide at least 9-10 hours of free time so that members could attend to nonwork issues (e.g., eating, laundry, correspondence, etc.) and prepare themselves for the sleep period. Most manning assessments do not allow for that level of specificity and while these assessments provide the necessary 8 hours for sleep, the sleep may be taken in multiple episodes. Fragmenting the 8 hours into two or more episodes may reduce the restorative value of the sleep.

\section{Building a Rational Manpower Requirement for the Navy}

The Navy's conundrum is to decide what definition of war to use for manpower requirements determination and the readiness-reporting guidelines. Congressional guidance tells the Navy to staff the fleet for sustained combat at sea. The Navy has defined the combat operational environment to be 60 days, threat probable in a three-axis threat environment (air, surface, and subsurface threats). If we staff platforms for a wartime scenario, then we are funding more manpower than we need to meet current and near-term future naval engagements. However, if we lower the baseline requirement assessment based on our most recent Navy warfighting experience, we have no demand signal to justify increasing the staffing level if the changing political landscape leads us back to the 60-day threat probable scenario. In that scenario, we would be forced to send ships into harm's way, inadequately staffed to meet the threat. Under these conditions, unless we achieve a quick and decisive victory with our technology, we will be in a vulnerable position. The $M+1$ 
metric was used to reflect the Navy's wartime manning requirement. Because we did not staff the platforms to that requirement, the Navy developed mobilization plans to bring the reserve Sailors onboard to make up the difference. However, as time passed, the $M+1$ term took on the meaning of an inflated requirement. The problem is that there is no empirical evidence based on research to suggest that the wartime manpower requirement (reflected in the $M+1$ metric) was wrong. Unfortunately, if the wartime scenario is accurately stated, then human performance may be the deciding factor in victory or defeat.

\section{Recommendations}

It is clear that the Navy is moving toward developing platforms that require a much smaller human footprint. Based on the research available, sleep-related fatigue is the limiting factor in sustaining combat at sea. As such, this limitation represents a major flaw in the Navy's afloat workload staffing methodology because it holds the workload as the hard constraint, failing to consider human preventative maintenance requirements. This construct rewards manpower planners for finding ways to leverage more productive work from sailors, while placing sailors' rest, nourishment, and hygiene at risk. Regardless of how the Navy may define future combat at sea, the workload construct misses the mark with respect to deploying platforms that can deliver sustained combat capability. To deliver sustained combat capability, the Navy must make human performance the controlling factor for determining personnel staffing levels and use

TABLE 6: Comparison of Current versus Proposed Navy Standard Workweek

\begin{tabular}{lcc}
\multicolumn{1}{c}{ Activity } & Current & Proposed \\
\hline On duty & 81 & $\mathbf{7 4}$ \\
\hline Productive work & 70 & 63 \\
\hline Training & 7 & 7 \\
\hline Service diversion & 4 & 4 \\
\hline Unavailable & $\mathbf{8 7}$ & $\mathbf{9 4}$ \\
\hline Sleep & 56 & 63 \\
\hline Messing & 14 & 14 \\
\hline Personal & 14 & 14 \\
\hline Sunday free time & 3 & 3 \\
\hline
\end{tabular}

minimal staffing constructs to optimize sailors' productive time after accounting for their personal needs. Making sailors' physiological requirements (sleep, nourishment, and hygiene) a primary constraint in the afloat manpower requirements determination methodology will lead to staffing numbers that support sustained combat capability. To account for sailors' sleep requirement, the Navy must address total sleep hours, sleep desynchrony, and sleep fragmentation. These needs can be accomplished through slight modifications to the Navy's standard workweek, changes to the Navy's culture, and modifications to berthing. Doing so will go a long way toward ensuring that sailors receive the high-quality sleep that they need to deliver sustained combat capability.

One step is to adjust the Navy's workweek to allow for 9 hours vice 8 hours of sleep per day. Taking this action reduces the Navy's productive workweek by 7 hours per week, as identified in

Table 6. The 7-hour reduction in the productive workweek will increase afloat staffing by some number, but that number will reflect the true requirement for a human to sustain combat capability beyond a couple of days. A change is needed in US Navy culture with respect to smarter watch rotations and increasing the Condition III watch sections from three to four.

These actions would provide a consistent work schedule that would eliminate the normal alertness troughs that humans exhibit, associated with the circadian rhythm, and thus significantly improve Sailor endurance and alertness. Table 7 depicts a 4-section, 3-hour watch rotation. Note that each section stands the same watch each day and that the nine hours between watches afford the Sailor the ability to achieve eight hours of continual sleep. Because the quality of sleep is equally as important as total hours and desynchrony, sleep fragmentation reduces the quality of one's sleep and promotes Sailor fatigue.

Eliminating sleep disruptions in berthing areas (e.g., ringing "Bells," passing the word, daily berthing inspections when sailors are sleeping, 


\section{TABLE 7: Proposed 4-Section, 3-Hour Watch Rotation}

\begin{tabular}{|c|c|c|c|c|c|c|c|c|}
\hline Watch Section & $00: 00-03: 00$ & 03:00-06:00 & 06:00-09:00 & 09:00-12:00 & $12: 00-15: 00$ & $15: 00-18: 00$ & $18: 00-21: 00$ & $21: 00-24: 00$ \\
\hline 1 & $X$ & & & & $X$ & & & \\
\hline 2 & & $X$ & & & & $X$ & & \\
\hline 3 & & & $X$ & & & & $X$ & \\
\hline 4 & & & & $x$ & & & & $X$ \\
\hline
\end{tabular}

reducing ambient light, noise from machinery adjacent to berthing locations, and proper air quality [temperature, humidity, and airflow]) will result in higher quality sleep.

The Navy should expand its investment in human systems integration, focusing on human performance as a critical component of total system performance. Thereby, we will ensure that future platforms have fully integrated the human strengths and weaknesses into the system design. Such actions will lead to the right answer, resulting in optimal use of scarce human resources. The Navy needs a better understanding of the consequences of these manning decisions if we are to deliver the level of combat capability required to protect our national interests abroad.

\section{References}

Andrews, C., "The Relationship between Performance and Sleep in United States Navy Recruits," Masters Thesis, Naval Postgraduate School, Monterey, CA, 2004

Belenky, G., N.J. Wesensten, D.R. Thorne, M.L. Thomas, H.C. Sing, and D.P. Redmond, "Patterns of performance degradation and restoration during sleep restriction and subsequent recovery: A Sleep DoseResponse Study," Journal of Sleep Research, Vol. 12, pp. 1-12, 2003.

Center for Naval Analysis, PowerPoint demonstratation of report findings, 2001.

Chief of Naval Operations (CNO) Nl (2001). "Hours of Work at Sea: An Empirical Analysis."

Comperatore, C., A. Kirby, C. Boch, and C. Ferry, "Alertness Degradation and Circadian Disruption on a U.S. Coast Guard Cutter Under Paragon Crewing Limits," Report No. CG-D-23-99, July 1999.

Dawson, D. and K. Reid, "Fatigue, alcohol, and performance improvement," Nature, London, 1997
Godfrey, A., "Optimizing Daytime Short Sleep Episodes to Maximize Performance in a Stressful Environment," Masters Thesis, Naval Postgraduate School, Monterey, CA., 2006

Hursh, S.R., D.P. Redmond, M.L. Johnson, D.R. Thorne, G. Belenky, T.J. Balkin, W.F. Storm, J.C. Miller, and D.R. Eddy, "Fatigue models for applied research in warfighting," Aviation, Space, and Environmental Medicine, Vol. 3, Supplement, 2004.

Miller, N.L., J. Dyche, C. Andrews, and T. Lucas, "Navy boot camp: Test score changes after two hour increase in sleep time," Proceedings of the Association of Professional Sleep Societies, Philadelphia, PA, 2004.

Miller, N.L., P. Matsagas, and L.G. Shattuck, "Fatigue and its effects on performance in military environments," In: Performance under Stress (P. Hancock and J. Szalma, Eds.). Ashģate Publishers. Aldershot, UK, in press.

Miller, N.L. and J. Nguyen, "Working the nightshift on the USS John C. Stennis: implications for enhancing warfighter effectiveness," Proceedings of the Second Humans Systems Integration Symposium, 2003.

Sandquist, T., M. Raby, A.L. Maloney, and T. Carvalhais, "Fatigue and alertness in merchant marine personnel: A Field Study of Work and Sleep Patterns," Report No. CG-D-06-97. Batelle Seattle Research Center and US Coast Guard Research and Development CenterConnecticut, 1996.

United States Code, Title X.

US Navy Instruction, OPNAVINST, 1000.

Van Dongen, H.P.A., G. Maislin, J.M. Mullinģton, and D.F. Dinges, "The cumulative cost of additional wakefulness: dose-response effects on neurobehavioral functions and sleep physiology from chronic sleep restriction and total sleep deprivation," Sleep, Vol. 26, pp. 2, 2003.

Wickens, C.D., J.D. Lee, Y. Liu, and S.E. Gordon Becker, An Introduction to Human Factors Engineering (2nd ed.), Pearson Prentice Hall, Upper Saddle River, NJ, 2004. 


\section{Huthor Biographies}

Nita Lewis Miller serves on the faculty of the NPS in Monterey, CA. Dr. Miller has an appointment in the Operations Research where she teaches human factors engineering, directs the Human Systems Integration Masters degree program, and pursues her research interests in fatigue and human performance. Dr. Miller was a postdoctoral fellow at the USAF School of Aerospace Medicine. She received her Ph.D. in Behavioral Sciences from the University of Texas, School of Public Health.

Captain Robert Firehammer is currently the Director of the US Navy Human Resource Center of Excellence located at the NPS in
Monterey, CA. He was formerly the Head Human Resource Community Manager and Detailer. He has held the following significant Navy Human Resource positions: Commanding Officer, Naval Manpower Analysis Center, Millington, Tennessee; Commanding Officer, Personnel Support Activity Pacific, Yokosuka, Japan; Head, Enlisted and Advancement Plans CNO 132C; Executive Officer, Shore Intermediate Maintenance Facility, Norfolk, VA; Fleet Personnel Readiness Officer, Commander Atlantic Fleet. Captain Firehammer has served as a Surface Warfare Officer on board USS Samuel B. Roberts FFG-58, USS Comte De Grasse DD-974, and USS America CV-66. He holds a Masters of Science Degree in Management from the NPS. 